\title{
Multilayered Endonasal endoscopic repair of CSF leaks of sphenoid sinus
}

\author{
Original \\ Mohamed Hussein Abdelazim ${ }^{1}$, Wael Fawzy Ismail', Ahmed Taha ${ }^{2}$ \\ Article \\ ${ }^{\text {I}}$ Otorhinolaryngology Department, Faculty of Medicine, Al-Azhar University, New Damietta, \\ Egypt. \\ ${ }^{2}$ Neurosurgery Department, Faculty of Medicine, Al-Azhar University, New Damietta, Egypt.
}

\begin{abstract}
Cerebrospinal fluid rhinorrhea of the sphenoid sinus is a serious clinical condition. Endoscopic management has become the gold standard treatment. Use of multilayer closure to occlude the anatomical defect was suggested by some reports. The current study aims to evaluate endoscopic repair of sphenoid sinus CSF leak using multilayer closure. The present study included 17 patients. Their CSF leak was caused by accidental trauma in 9 patients (52.9\%), iatrogenic trauma in 1 patient $(5.9 \%)$ and in 7 patients $(41.1 \%)$, the leak occurred spontaneously. After localization of the leak, multilayer closure was used for anatomical defect repair. All patients achieved successful operative repair form the first attempt. The reported complications included meningitis in only 1 patient (5.9\%).Endoscopic repair of the sphenoid sinus CSF leaks using multilayer closure is a safe and effective approach. The Hadad-Bassagasteguy flap is the corner stone for sealing skull base defects in sphenoid sinus.
\end{abstract}

Key Words: Endoscopic, rhinorrhea, sphenoid sinus

Received: 10 April 2018, Accepted: 31 May 2018

Corresponding Author: Mohamed Hussein Abdelazim, Department of Otorhinolaryngology, Al-Azhar Faculty of Medicine New Damietta; Egypt. Tel.: +20473860840, E-mail: mohammedabdelazeem35@yahoo.com

ISSN: 2090-0740, June 2018, Vol.19, No.2

\section{INTRODUCTION}

Cerebrospinal fluid (CSF) rhinorrhea is a dangerous and potentially fatal condition resulting from abnormal communication between subarachnoid space and the nasal cavity. In most instances, it is attributed to iatrogenic trauma associated with surgical interventions including sinus and skull base surgeries while spontaneous CSF rhinorrhea is relatively rare ${ }^{[1]}$.

CSF leaks rarely arise from the sphenoid sinus ${ }^{[2]}$. Clinically, the condition is characterized by the so-called tea-pot sign. On forward bending of the patient head, CSF will flow through the sphenoid ostium ${ }^{[3]}$.

Fortunately, most CSF leaks respond to conservative treatment and close spontaneously. However, failure to achieve such response is a clear indication of surgical interference. Other indications include CSF leaks following extensive injury or intra-operative detection of CSF leaks ${ }^{[4]}$. Proper selection of the surgical repair method of sinonasal CSF leak is essential to avoid the hazardous consequences of failed surgery including meningitis and brain abscesses ${ }^{[5]}$.

Management of sphenoid sinus CSF leaks is a particularly demanding procedure. Surgeons are confronted by the combined difficulties of surgical access and visualization. Multiple bony, cartilaginous and soft tissue autologous flaps besides other heterologous and synthetic materials were used to obliterate CSF leaks. However, use of multi-layer flaps proved to be associated with better outcome $\mathrm{e}^{[3,4]}$.

The Hadad-Bassagasteguy vascularized nasoseptal pedicled flap (HBF) is an effective technique for reconstruction of skull base defects ${ }^{[6]}$.

The present study aims to evaluate the use of multilayered closure in the management of sphenoid sinus CSF leaks.

\section{MATERIALS AND METHODS:}

The present prospective study was carried on 17 patients with established diagnosis of sphenoid sinus CSF rhinorrhea. They were recruited from the Otorhinolaryngology Department at Al-Azhar University, New Damietta, Egypt from April 2015 to December 2017. The study was approved by the local ethical committee and informed consent was obtained from participating patients.

\subsection{Preoperative assessment}

All patients were subjected to careful history taking and thorough otorhinolaryngological, endoscopic and neurological examination. The CSF nature of the rhinorrhea fluid was confirmed by elevated levels of beta- 2 transferrin 
and/or beta-trace protein in the fluid samples. Localization of the leak was achieved using multidetector computed tomography (MDCT) (Figs. 1-4) and magnetic resonance cisternography (Fig. 5).

\subsection{Operative technique}

Intraoperatively, the CSF fluid was apparent in some cases dribbling through normal ostium of the sphenoid (fig.6). The CSF leak was further localized using intrathecal fluorescein injection. In most cases except when the defect was in the lateral recess surgery started with surgical exposure using partial middle turbinectomy to widen the surgical access. Sphenoidotomy was done with complete anterior wall removal (fig.7). In cases with lateral recess leak endonasal transpterygoid approach was used starting with removal of the posterior half of the inferior turbinate at the same side of the defect. The lower half of the middle turbinate also was removed and wide middle meatal antrostomy was done. The medial one third of the posterior wall of the maxillary sinus was drilled. The sphenopalatine and descending palatine arteries were cauterized using bipolar diathermy. Sphenoidotomy was done with complete removal of the anterior wall of the sphenoid sinus. The pterygoid wedge and its attachment to the sphenoid body was drilled and the lateral recess was then fully exposed. In cases when encephalocele was present it was cauterized by bipolar diathermy till exposure of the site of the defect (fig.8). In all cases the defect area was prepared for grafting by removing the surrounding mucoperiosteum. In cases where the defect was larger than $5 \mathrm{~mm}$ the basic multi-layer closure consisted of an underlay and overlay fascia lata grafts and septal cartilage in between (sandwich technique). In addition, a fat plug is inserted to fill the sinus cavity and help stabilize the sandwich graft. Finally, an HBF was harvested and rotated into the

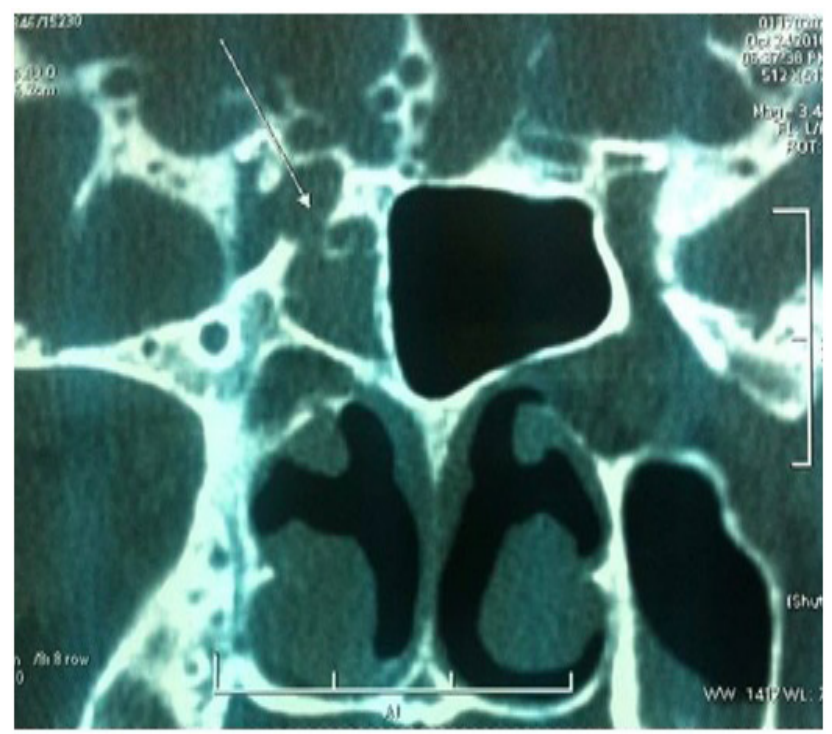

Fig 1 : Cone beam CT the arrow is pointing to the site of the leak in tuberculum sphenoidal sphenoid to reconstruct the defect in a multilayered fashion (Figs. 9-14). In only 3 cases (1 tuberculum, 1 lateral recess and 1 midclival) where the defect was smaller than $5 \mathrm{~mm}$ it was closed using dumbbell fat then fasia lata overlay graft then surgicel strips and HBF. No tissue glues were used. Additional support of the graft was achieved using surgicel strips and sofratol nasal pack in all cases.

\subsection{Postoperative management and follow up}

Patients were kept on antibiotics, with bed rest, head elevation, refraining from nasal blowing and cough for 10-14 days. Postoperative follow-up included endoscopic nasal suctioning and care of the nasal wound at regular intervals of 5-7 days for 3-4 weeks until healing of the cavity (fig15).

\section{RESULTS}

Patients included in the present study comprised 11 males $(64.7 \%)$ and 6 females $(35.3 \%)$. They had an age of $40.2 \pm 4.7$ years. The cause of CSF rhinorrhea was accidental trauma in 9 patients $(52.9 \%)$, iatrogenic trauma in 1 patient $(5.9 \%)$ and in 7 patients $(41.1 \%)$, the leak occurred spontaneously. The site of leak was diagnosed to be the lateral Sternberg canal in 6 patients $(35.3 \%)$, the planum in 7 patients $(41.2 \%)$, the tuberculum in 3 patients $(17.6 \%)$ and the midclavius in 1 patient $(5.9 \%)$. In 14 patients $(82.3 \%)$ the defect was greater than $5 \mathrm{~mm}$ and in 3 patients $(17.7 \%)$ the defect was smaller than $5 \mathrm{~mm} 2$ different composite graft were used according to the size of the defect as described in the surgical technique however HBF was used in all cases. In our series, all patients achieved successful operative repair from the first attempt. The reported complications included meningitis in only 1 patient $(5.9 \%)$.

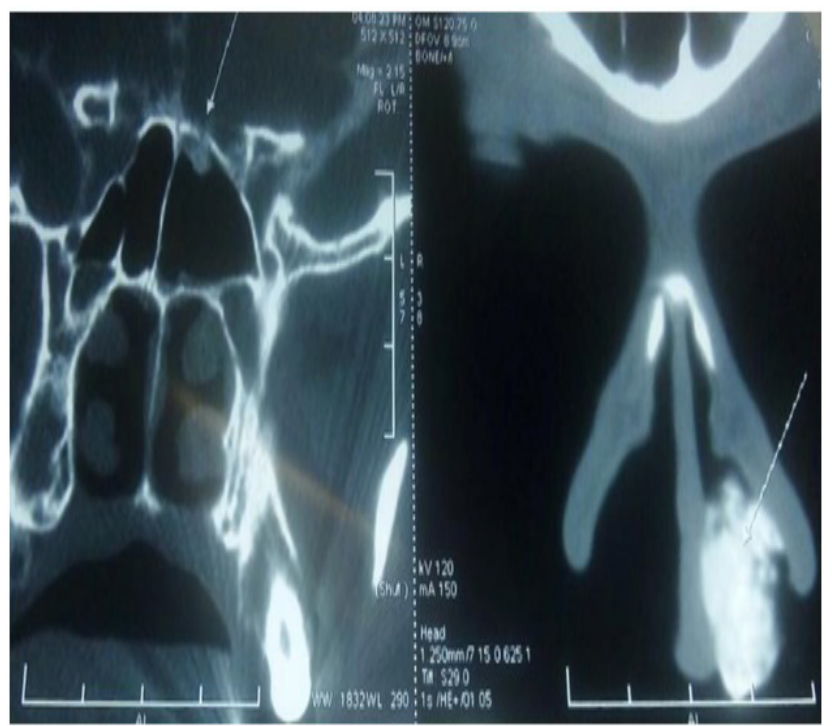

Fig 2 : CT scan showing CSF leak in region of planum sphenoidale 


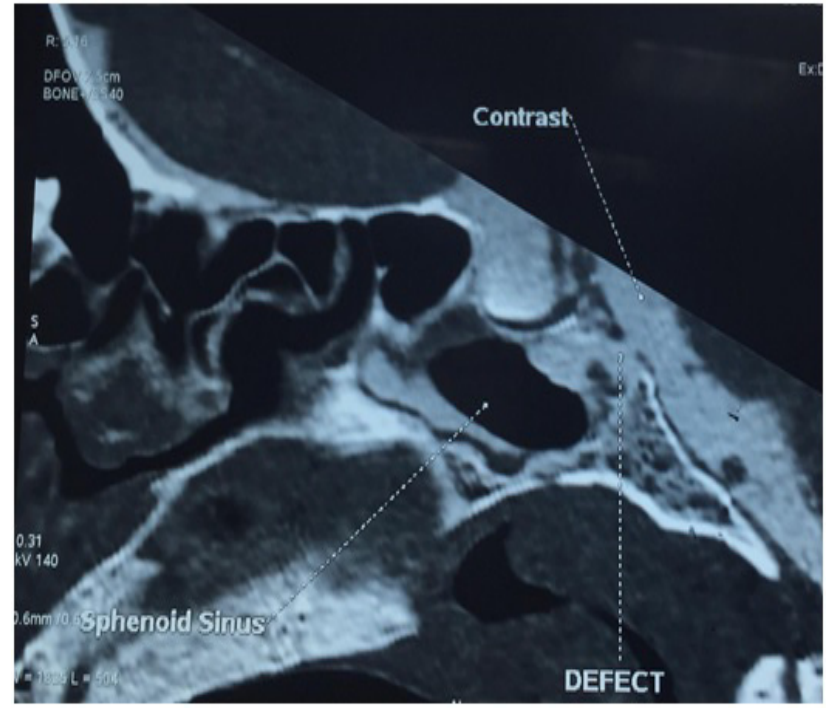

Fig 3: Sagittal CT image showing defect in the clival region

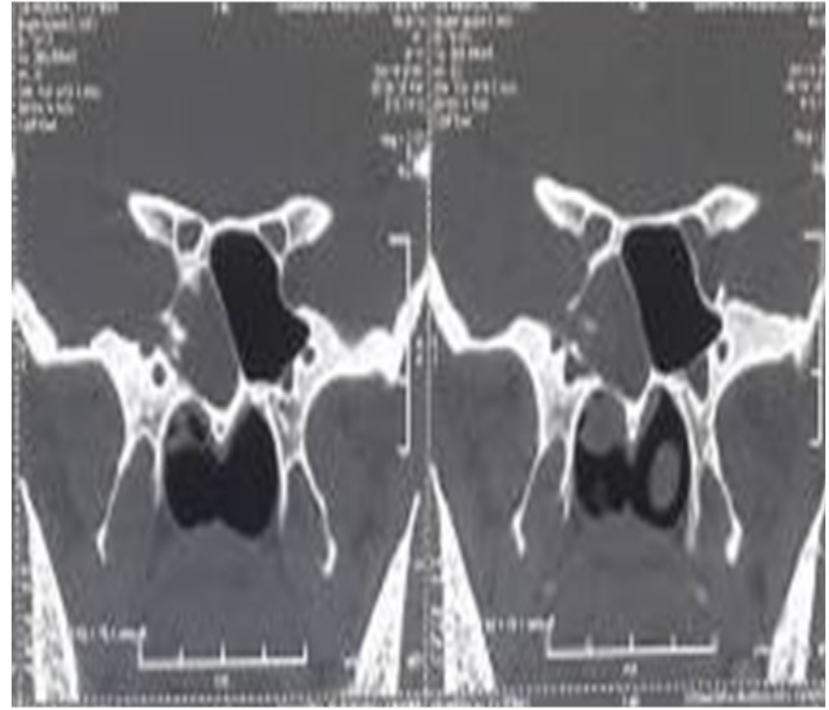

Fig 4: Coronal CT image showing defect in the roof of the lateral recess of the right sphenoid sinus

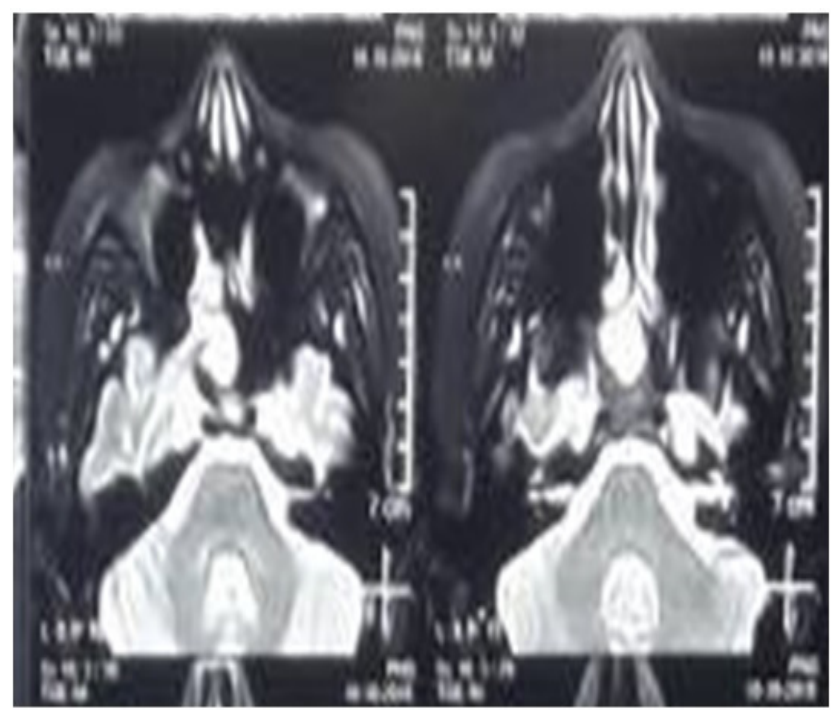

Fig 5 : MRI T2 spheniod CSF leak with mengioencephalocele

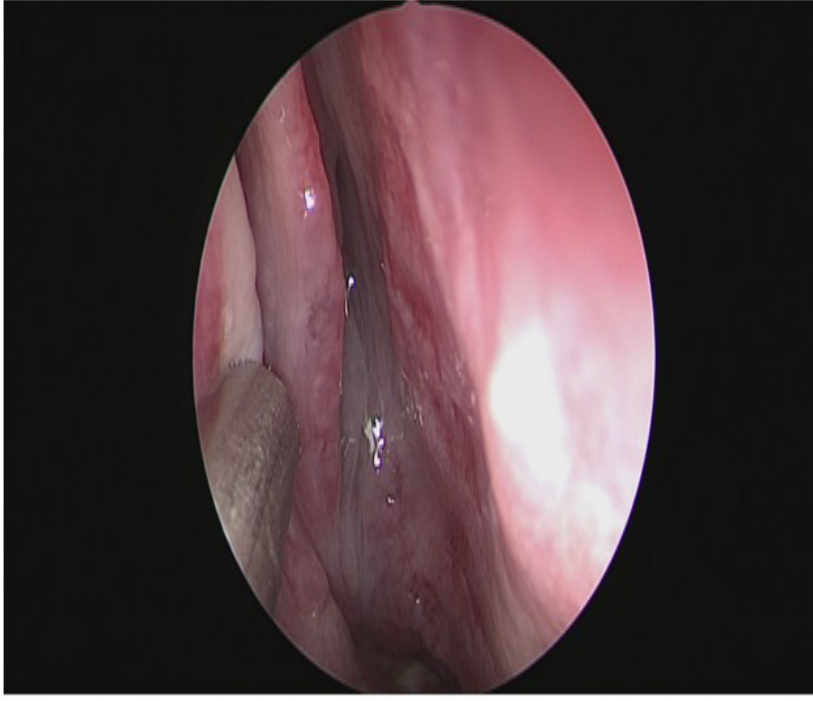

Fig 6: surgical veiw Endoscopic examination CSF apears in the sphenoethmodal recess

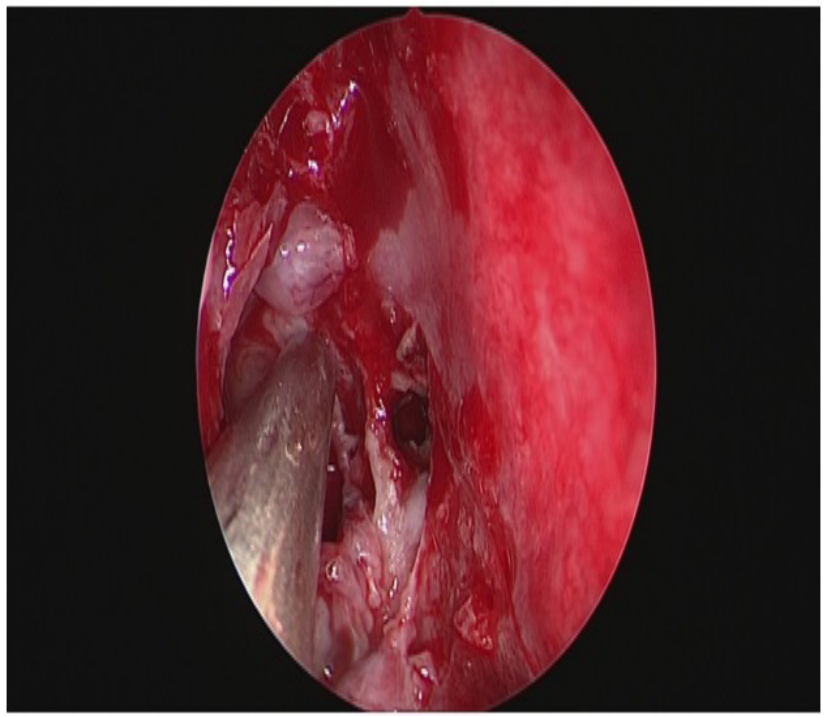

Fig 7: Meningocele appearing through the defect in sphenoid sinus after sphenoidotomy and removal of anterior wall

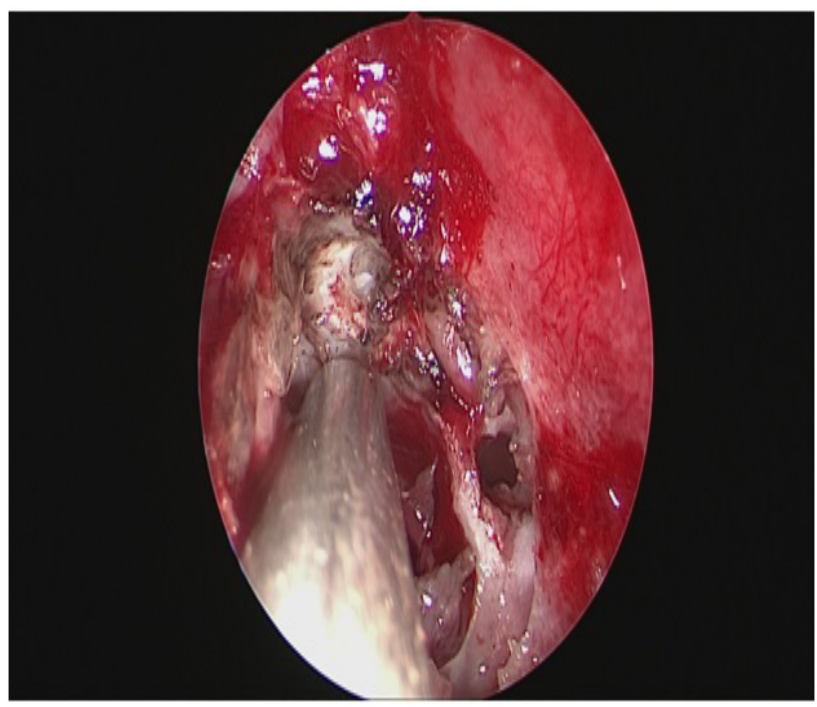

Fig 8 : Site of the leak after cauterization of meningocele 


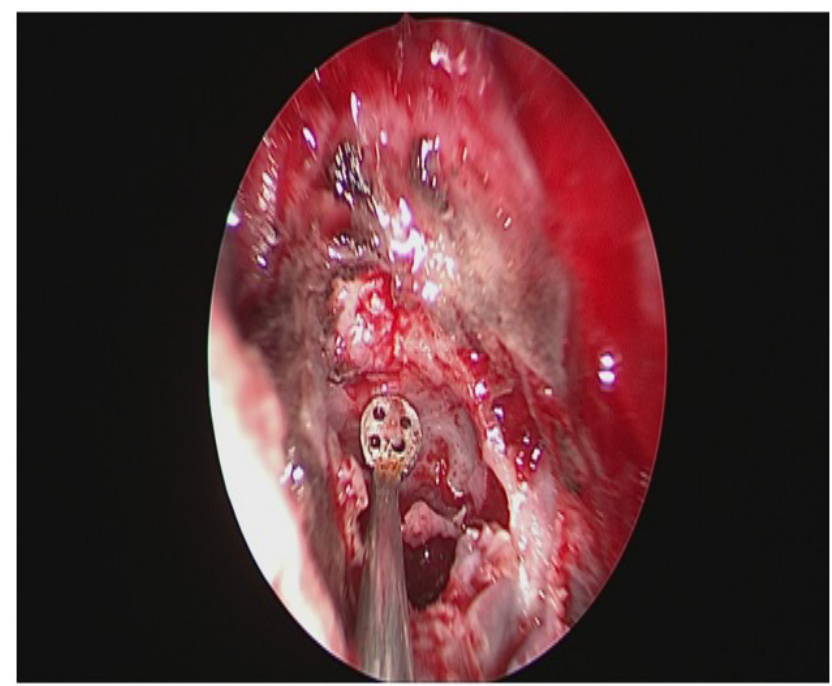

Fig $9: 1$ st layer of closure using underlay fascia lata graft

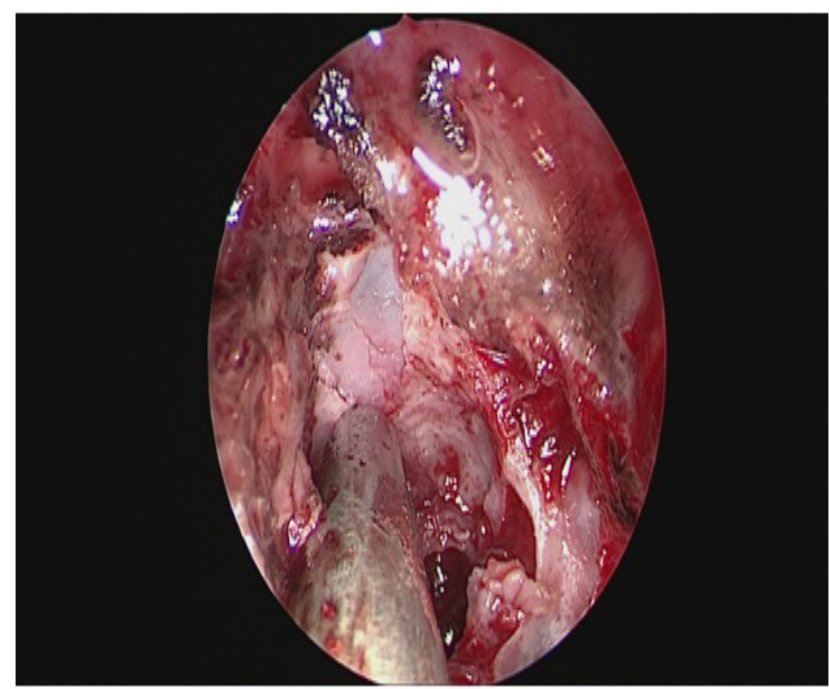

Fig 10 : 2nd layer of multilayer using closure underlay septal cartilage graft

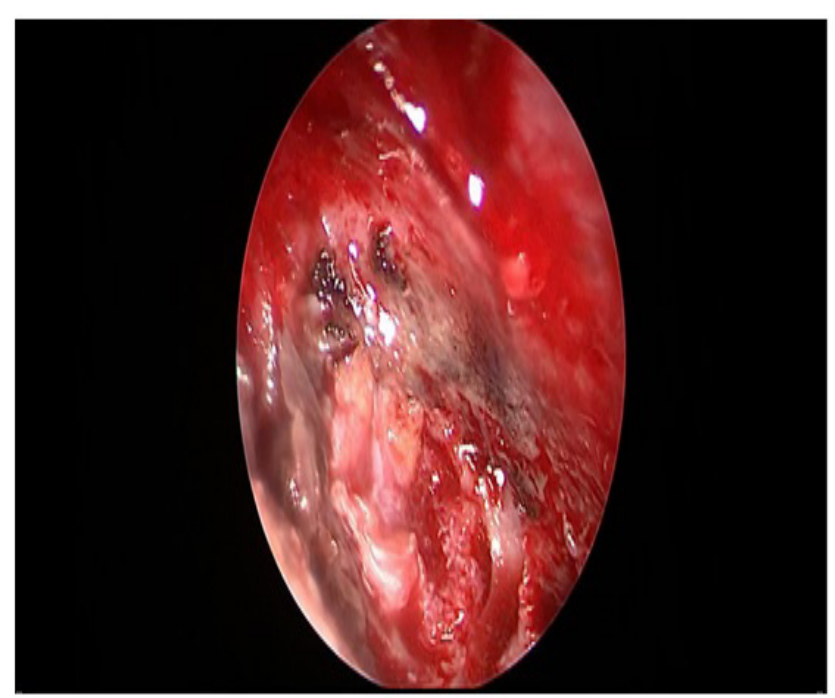

Fig 11 : fascia lata as 3rd layer graft overlay

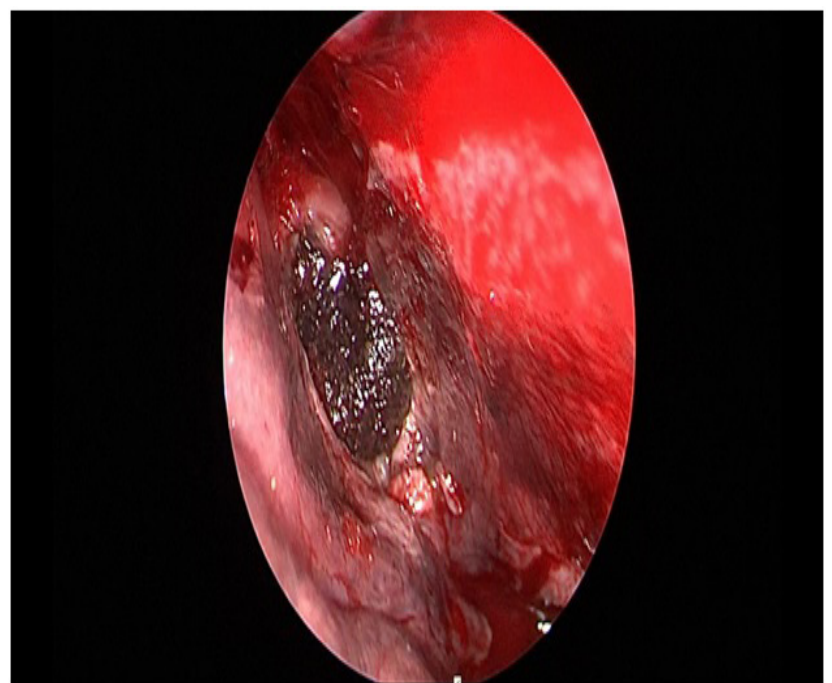

Fig 12 : surgicel strips in place

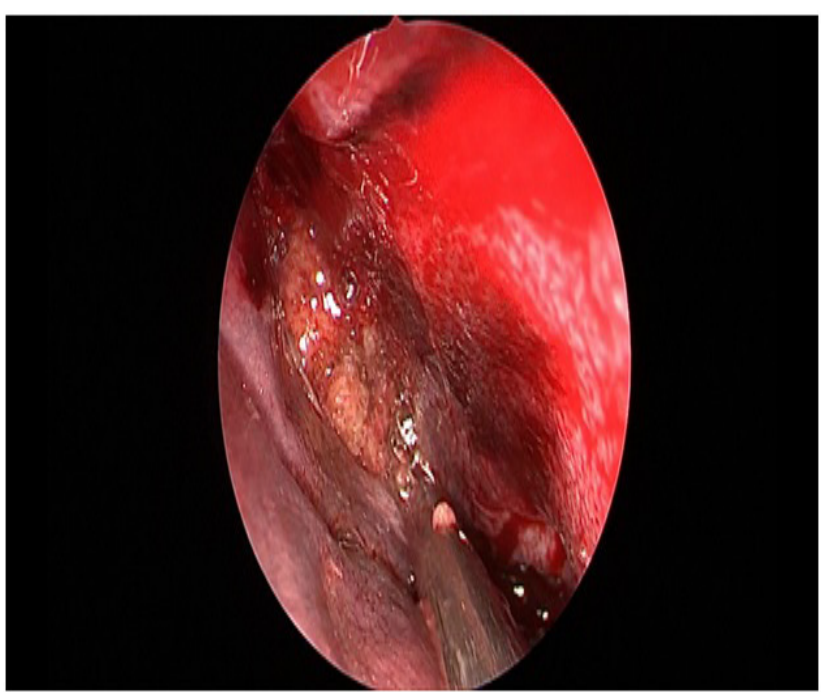

Fig 13 : a fat plug is inserted to fill the sinus cavity and help stabilize the sandwich graft

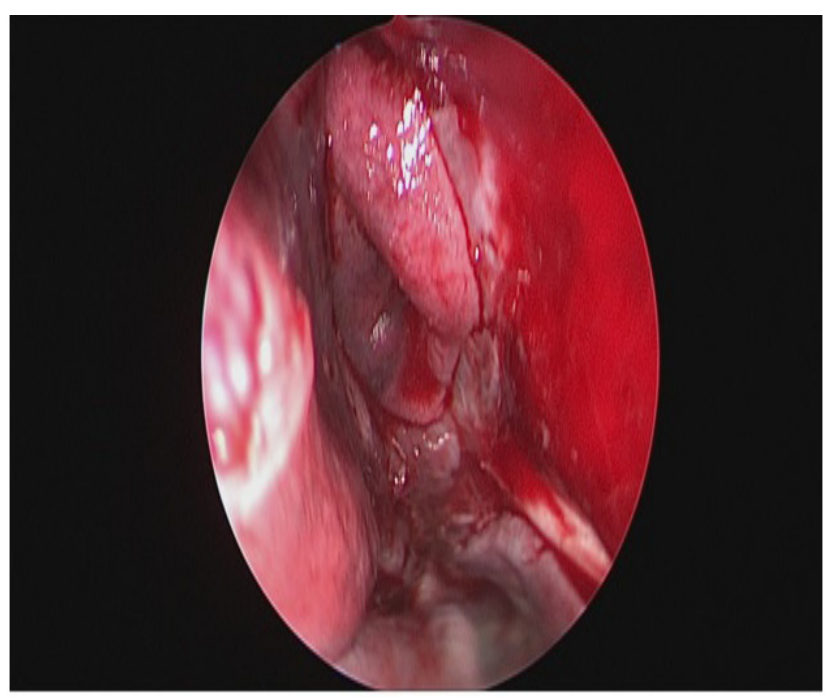

Fig 14 : HBF was harvested and rotated into the sphenoid to reconstruct the defect in a multilayered fashion 


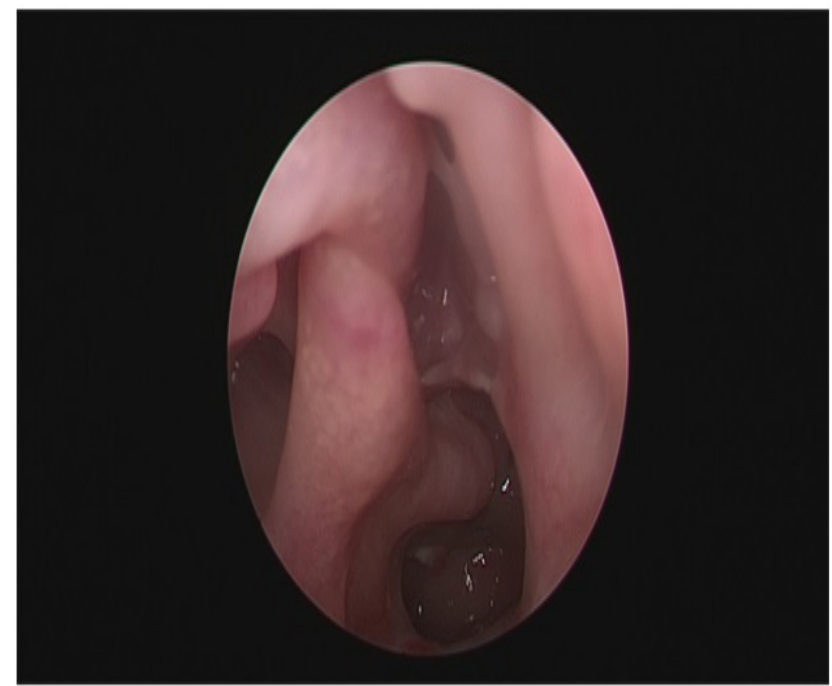

Fig 15 : endoscopic view of postoperative healed crossed HBF in 4weeks follow up visit.

\section{DISCUSSION}

Introduction of endonasal endoscopic techniques has resulted in dramatic progress in the management of CSF leaks. This approach proved to be especially valuable in situations where narrow surgical field together with the difficult visualization of the anatomical defect constitute a complex challenge to surgical intervention ${ }^{[7]}$.

There are many anatomical and etiological considerations that determine the endoscopic repair of CSF leaks affecting the sphenoid sinus. The sinus is formed by the anterior and middle cranial fossae, is in close proximity to the internal carotid artery and optic nerve, and may have extreme lateral pneumatization that limits accessibility via normal endoscopic routes ${ }^{[8]}$.

In the present study, use of this technique resulted in excellent outcome. All patients provided clinical and radiological evidence of healing of CSF leaks with only one case that was complicated by meningitis.

The use of combined grafts adding cartilage to the fascia lata in the management of CSF leaks was reported by many studies ${ }^{[9,10]}$. The same principle was applied using multilayer acellular dermis for repair of CSF leaks ${ }^{[1]}$.

In a recent report and in support of our results, have achieved a $95 \%$ success rate in managing CSF leaks in 40 patients in the first attempt repair and 100 $\%$ success rate after second attempt repair ${ }^{[4]}$. They managed CSF leaks affecting lateral lamella of the cribriform, cribriform plate and sphenoid sinus.

Furthermore, endoscopic multilayer technique was used in 42 patients with traumatic CSF rhinorrhea ${ }^{[12]}$. The study found that none of the studied patients developed serious intra- or postoperative complications. Only one case required another surgery to repair a missed second defect. They concluded that post-traumatic CSF leaks can be successfully managed via the endonasal endoscopic route using the multilayer repair technique. Also, the similar technique was used on 36 patients with CSF rhinorrhea with a favorable outcome in $100 \%$ of cases $^{[13]}$.

Use of multi-layered flap in the management of CSF leaks provided a successful obliterating material for the anatomical defect. This flap adds the stiffness of the bony or cartilaginous tissue to the elasticity and sealing capability of the soft tissues ${ }^{[14,15]}$.

\section{CONCLUSION}

Endoscopic repair of the sphenoid sinus CSF leaks using multilayer closure is a safe and effective approach. The Hadad-Bassagasteguy flap is the corner stone for sealing skull base defects in sphenoid sinus.

\section{CONFLICT OF INTEREST}

There are no conflicts of interest.

\section{REFERENCES}

1. Nyquist GG, Anand VK, Schwartz TH Endoscopic management of cerebrospinal fluid rhinorrhea. Oper Tech Otolaryngol 2011; 22:229-231

2. Shetty PG, Shroff MM, Fatterpekar GM, Sahani DV, Kirtane MV. A retrospective analysis of spontaneous sphenoid sinus fistula: MR and CT findings. Ajnr Am J Neuroradiol. 2000; 21: 337-342.

3. Sautter NB, Batra PS, Citardi MJ. Endoscopic management of sphenoid sinus cerebrospinal fluid leaks. Ann Otol Rhinol Laryngol. 2008;117:32-39.

4. Saafan ME, Albirmawy OA, Tomoum MO (2014) Sandwich grafting technique for endoscopic endonasal repair of cerebrospinal fluid rhinorrhoea. Eur Arch Otorhinolaryngol 2014; 271: 1073-1079

5. Lee DH, Lim SC, Joo YE. Treatment outcomes of endoscopic repairs of sinonasal cerebrospinal fluid leaks. J Craniofac Surg 2011; 22:1266-1270.

6. Brunworth J, Lin T, Keschner DB, Garg R, Lee JT. Use of the Hadad-Bassagasteguy flap for repair of recurrent cerebrospinal fluid leak after prior transsphenoidal surgery. Allergy Rhinol (Providence) 2013; 4: 155-161.

7. Tosun F, Carrau RL, Snyderman CH, Kassam A, Celin S, Schaitkin B. Endonasal endoscopic repair of 
cerebrospinal fluid leaks of the sphenoid sinus. Arch Otolaryngol Head Neck Surg 2003; 129: 576-580.

8. Woodworth BA, Neal JG, Schlosser RJ. Sphenoid sinus cerebrospinal fluid leaks. Operative Techniques in Otolaryngology 2006; 17:37-42

9. El-Banhawy OA, Halaka AN, El-Hafiz Shehab ElDien A, Ayad H. Subcranial transnasal repair of cerebrospinal fluid rhinorrhea with free autologous grafts by the combined overlay and underlay techniques. Minim Invasive Neurosurg 2004; 47: 197-202.

10. Locatelli D, Rampa F, Acchiardi I, Bignami M, De Bernardi F, Castelnuovo P. Endoscopic endonasal approaches for repair of cerebrospinal fluid leaks: nine-year experience. Neurosurgery 2006; 58: 246-256

11. Ismail AS, Costantino PD, Sen C. Transnasal Transsphenoidal Endoscopic Repair of CSF Leakage
Using Multilayer Acellular Dermis. Skull Base 2007; 17:125-132.

12. Ibrahim AA, Okasha M, Elwany S. Endoscopic endonasal multilayer repair of traumatic CSF rhinorrhea. Eur Arch Otorhinolaryngol 2016; 273: 921-926.

13. Mishra SK, Mathew GA, Paul RR, Asif SK, John M, Varghese AM, Kurien M. Endoscopic Repair of CSF Rhinorrhea: An Institutional Experience. Iran J Otorhinolaryngol 2016; 28:39-43.

14. Tormenti MJ, Paluzzi A, Pinheiro-Nieto C. Endoscopic endonasal repair of spontaneous CSF fistulae. J Neurosurg 2012; 32:E6.

15. Mortuaire G, Vandeville S, Assaker R. Endoscopic repair of anterior or middle skull base cerebrospinal fluid leaks after tumour resection. Eur Ann Otorhinolaryngol Head Neck Dis 2012; 129:77-81. 